\title{
PERAN BADAN PENGAWAS OBAT DAN MAKANAN (BPOM) TERKAIT DENGAN PEREDARAN OBAT TRADISIONAL ILEGAL MONTALIN DI KOTA DENPASAR*
}

\author{
Oleh : \\ Ida Ayu Dinda Laksmi Pidada** \\ Ida Bagus Putu Sutama*** \\ I Made Dedy Priyanto*** \\ Program Kekhususan Hukum Bisnis, Fakultas Hukum Universitas \\ Udayana
}

\begin{abstract}
Abstrak
Jamu atau dikenal dengan obat tradisional mempunyai kedudukan yang khusus karena merupakan warisan budaya di bidang kesehatan di Indonesia. Berdasarkan Peraturan Menteri kesehatan Nomor 246/Menkes/Per/V/1990 Pengertian obat tradisional adalah bahan atau ramuan bahan yang berupa bahan tumbuhan, bahan hewan, bahan mineral, sediaan galenik atau campuran dan bahan-bahan tersebut, yang secara tradisional telah digunakan untuk pengobatan berdasarkan pengalaman. Yang dibahas dalam penelitian ini adalah kesadaran hukum pelaku usaha serta konsumen sebagai penjual dan pembeli obat tersebut dan bagaimana peran Badan Pengawas Obat dan Makanan (BPOM) terkait peredaran obat tradisional ilegal montalin di Kota Denpasar.

Metode penelitian yang digunakan adalah metode penelitian empiris dengan menggunakan pendekatan perundang-undangan dan pendekatan fakta. Dalam penelitian ini data dan sumber data yang digunakan adalah data primer berupa hasil wawancara di lapangan dan data sekunder berupa Undang-Undang Perlindungan Konsumen No 8 Tahun 1999, Peraturan Presiden Republik Indonesia Nomor 80 Tahun 2017 tentang Badan Pengawas Obat Dan Makanan, KUHPerdata.

Dari hasil penelitian ini dapat disimpulkan (1) berdasarkan wawancara yang telah dilakukan bahwa pelaku usaha belum memiliki kesadaran hukum terkait penjualan obat tradisional ilegal montalin, responden pun masih belum memahami mengenai

\footnotetext{
* Penulisan karya ilmiah merupakan ringkasan skripsi.

** Ida Ayu Dinda Laksmi Pidada, 1516051274, Mahasiswa S1 Reguler Sore FH UNUD

${ }^{* * *}$ Ida Bagus Putu Sutama adalah dosen Fakultas Hukum Universitas Udayana

**** I Made Dedy Priyanto adalah dosen Fakultas Hukum Universitas Udayana
} 
obat tradisional, dasar hukum serta sanksinya. (2) Peran BPOM terkait dengan peredaran obat tradisional ilgal montalin di Kota Denpasar cukup jelas bahwa BPOM sudah rutin melaksanakan pengawasan dibidang pemeriksaan dan apabila ditemukan beredar obat montalin lagi maka BPOM tidak segan "memberi sanksi yang tegas sesuai dengan peraturan perundangundangan yang berlaku.

Kata kunci : Perlindungan Hukum, Konsumen, Pelaku Usaha, Obat Tradisional Ilegal Montalin

\begin{abstract}
Health is the most important necessity of life, if a person is sick then he will see a doctor and buy medicine if diagnosed requires special treatment. In Indonesia, herbal medicine or traditional medicine has a special position because it is a cultural heritage in the health sector. The definition of traditional medicine based on the Minister of Health Regulation Number 246 / Menkes / Per / V / 1990 states that traditional medicines are ingredients or ingredients in the form of plant materials, animal ingredients, mineral materials, galenic preparations or mixtures and materials, which are traditionally has been used for treatment based on experience. What was discussed in this study was the legal awareness of business people as well as consumers as sellers and buyers of these drugs and how the role of the Food and Drug Supervisory Agency (BPOM) was related to the circulation of traditional illegal drugs in the city of Denpasar.

The research method used is an empirical research method using the statutory approach and factual approach. Data and sources of data used in this study are primary data in the form of interviews in the field and secondary data in the form of Consumer Protection Act No. 8 of 1999, Presidential Regulation of the Republic Indonesia Number 80 of 2017 concerning Drug and Food Supervisory Agency, Civil Code.

From the results of this study, it can be concluded (1) based on interviews conducted that business actors do not have legal awareness regarding the sale of traditional illegal montalin drugs, respondents also still do not understand about traditional medicine, legal basis and sanctions. (2) The role of BPOM related to the circulation of ilgal montalin traditional drugs in Denpasar City is quite clear that BPOM has routinely carried out supervision in the field of inspection and if montalin drugs are circulating again, BPOM does not hesitate to give strict sanctions in accordance with laws and regulations.
\end{abstract}


Keywords: Legal Protection, Consumers, Business Executors, Montalin Illegal Traditional Medicine

\section{Pendahuluan}

\subsection{Latar Belakang}

Dalam perkembangan kelangsungan hidup manusia, setiap orang yang menginginkan hidup sehat akan melakukan berbagai upaya atau cara untuk memulihkan keadaannya secara cepat dan optimal dengan menggunakan berbagai macam obat. Bahkan tak jarang dari mereka yang ingin tampil sempurna rela mengorbankan uangnya untuk mendapatkan kesempurnaan itu dengan mengkonsumsi berbagai macam obat. ${ }^{1}$ Di Indonesia, jamu atau obat tradisional mempunyai kedudukan yang khusus karena merupakan warisan budaya di bidang kesehatan. Obat tradisional adalah bahan atau ramuan bahan yang berupa bahan tumbuhan, bahan hewan, bahan mineral, sediaan galenik atau campuran dan bahan-bahan tersebut, yang secara tradisional telah digunakan untuk pengobatan berdasarkan pengalaman.

Adanya perdagangan bebas mengakibatkan barang atau jasa yang beredar belum tentu menjamin keamanan, keselamatan dan kesehatan konsumen. Badan Pangan Obat dan Makanan (yang selanjutnya disebut dengan BPOM) menarik obat tradisional dari peredaran. Puluhan item obat tradisional berbagai merk berjejer rapi di meja ruangan tamu Kepala BBPOM Kota Denpasar, Bali, Rabu (9 September 2015) siang. Seluruh obat tersebut merupakan hasil operasi BBPOM Denpasar selama beberapa bulan terakhir atas produk obat tradisional mengandung bahan kimia obat yang beredar di pasaran. Setidaknya ada 50 item produk obat tradisional mengandung bahan kimia obat yang menjadi public warning dari BBPOM Denpasar, dan 25 di antaranya merupakan produk ilegal tanpa izin edar. ${ }^{2}$

Dari pemberitaan diatas salah satu yang akan dibahas adalah obat ilegal montalin. Obat Montalin adalah obat tradisional yang berbentuk tablet, obat ini di klaim dapat menyebuhkan pegal linu dan penyakit asam urat yang khasiatnya sudah sangat

${ }^{1}$ G. Eka Putra Pratama Arnawa dkk, 2018 "Pengawasan Terhadap Perusahaan Yang Mengedarkan Obat-Obatan Impor Tanpa Izin Edar”, Jurnal Fakultas Hukum Universitas Udayana, Denpasar, h. 2. URL https://ojs.unud.ac.id/index.php/kerthasemaya/article/view/44828 . Diakses pada tanggal 17 Juni 2019

2 Tribun News, 2015, “Obat Kuat yang Kini Tren di Bali Ternyata Mengandung Bahan Kimia", Serial Online, Oktober-November, URL http://www.tribunnews.com/regional/2015/09/10 /obat-kuat-yang-kini-tren-di-bali-ternyatamengandung-bahan-kimia , diakses pada tanggal 30 Oktober 2018 
terbukti ampuh dan cepat dalam menyebuhkan pegal linu maupun asam urat. Kandungan Obat Montalin ini terbukti dicampuri dengan Bahan Kimia Obat Keras (BKO) berjenis paracetamol, sildanefil, dan natrium diklofenakdan serta tidak memiliki izin resmi dari BPOM, apabila diperjual belikan tanpa resep dan pengawasan dari dokter dapat membahayakan kesehatan dan bahkan dapat menyebabkan iritasi kulit, gangguan saluran cerna dan gangguan fungsi hati. ${ }^{3}$

Terhadap permasalahan ini Balai Besar Pengawas Obat dan Makanan (BBPOM) pada umumnya memiliki peran yang sangat besar. Keputusan Kepala Badan Pengawas Obat dan Makanan No. 05018/SK/KBPOM tentang Organisasi dan Tata Kerja Unit Pelaksanaan Teknis dilingkungan Balai Pengawas Obat dan Makanan, dalam Pasal 2 menyebutkan Unit pelaksanaan teknis dilingkungan Balai Besar Pengawasan Obat dan Makanan mempunyai tugas melaksanakan kebijakan dibidang pengawasan produk terapetik, narkotika, psikotropika dan zat adiktif lain, obat tradisional, kosmetik, produk komplimen, keamanan pangan dan bahan berbahaya.

Dalam hal ini Balai Besar Pengawas Obat Dan Makanan mempunyai Kewajiban dalam menangani kejadian - kejadian yang berdampak merugikan hak -hak dari pada Konsumen khususnya pada produk olahan obat dan makanan, hak paling mendasar ialah mendapatkan informasi yang benar. ${ }^{4}$ BBPOM mempunyai kewenangan untuk menentukan produksi obat tradisional apa yang boleh diproduksi dan dikonsumsi oleh konsumen serta mempunyai hak dalam memberikan sanksi kepada pelaku usaha atau produsen yang memproduksi obat tradisional berbahaya bagi konsumen, sehingga kepentingan konsumen dapat terlindungi yaitu mengkonsumsi obat tradional yang aman dan memenuhi syarat bagi kesehatan.

\subsection{Rumusan Masalah}

1. Apakah faktor penyebab peredaran obat tradisional ilegal montalin masih diperjual belikan di Kota Denpasar?

2. Bagaimanakah peran BPOM terkait dengan peredaran obat tradisional ilegal montalin di Kota Denpasar?

\footnotetext{
${ }^{3}$ Balai Besar/Balai POM Kota Denpasar, 2014, "Konferensi Pers Produk Ilegal dan Mengandung Bahan Berbahaya", Serial Online, Oktober-November, URL :

https://www.pom.go.id/new/view/more/berita/7146/Konferensi-Pers-Produk-Ilegal-dan-

Mengandung-Bahan-Berbahaya.html . Diakses pada tanggal 24 Juni 2019

${ }^{4}$ Gede Jaya Kesuma dkk, 2018, "Peranan Balai Besar Pengawas Obat Dan Makanan Provinsi Bali dalam memberikan perlindungan terhadap konsumen dengan peredaran obat yang mengandung zat berbahaya (Policresulen)" , Jurnal Fakultas Hukum Universitas Udayana, Denpasar, h. 3. URL : https://ojs.unud.ac.id/index.php/kerthasemaya/article/view/41656 . Diakses pada tanggal 17 Juni 2019
} 


\subsection{Tujuan Penulisan}

Tujuan penelitian ini adalah untuk memahami tentang faktor penyebab peredaran obat tradisional ilegal montalin masih di perjual belikan di Kota Denpasar dan untuk memahami tentang peran BPOM terkiat dengan peredaran obat tradisional ilegal montalin di Kota Denpasar.

\section{Hasil Dan Analisis Data}

\subsection{Metode Penulisan}

Jenis penelitian yang digunakan adalah penelitian yuridis empiris dengan menggunakan Pendekatan Perundang-undangan (Statute Approach) dan Pendekatan Fakta (Fact Approach). Artinya dalam menelaah permasalahan yang ada dikaji berdasarkan fakta lapangan dan ditunjang dengan disiplin ilmu hukum serta peraturan perundang-undangan yang ada kaitanya dengan permasalahan yang akan dibahas. 5

\subsection{Penyebab Obat Montalin Masih Diperjualbelikan Di Kota Denpasar}

1. Kesadaran Hukum Pelaku Usaha Terkait Penjualan Obat Ilegal Tradisional Montalin di Kota Denpasar

Kesadaran hukum menurut Soerjono Soekanto merupakan kesadaran atau nilai-nilai yang terdapat di dalam diri manusia tentang hukum yang ada atau tentang hukum yang diharapkan ada. Sebenarnya yang ditekankan adalah nilai-nilai tentang fungsi hukum dan bukan suatu penilaian hukum terhadap kejadiankejadian yang konkrit dalam masyarakat yang bersangkutan. ${ }^{6}$ Dapat dipahami kesadaran hukum dianggap sebagai mediator antara hukum dengan pola perilaku dalam masyarakat baik secara individu maupun kolektif. Kesadaran hukum menyangkut aspek kognitif dan perasaan yang sering sekali dianggap sebagai faktor yang mempengaruhi hubungan antara hukum dengan pola perilaku dalam masyarakat. Artinya apabila seseorang memiliki kesadaran hukum, maka mampu membedakan antara perbuatan yang boleh dan tidak boleh dilakukan. Kesadaran hukum mempunyai "empat (4) indikator, antara lain: ${ }^{7}$

a. Pengetahuan hukum yaitu pengetahuan pelaku usaha atau produsen akan adanya peraturan mengenai pentingnya izin edar untuk obat yang di produksi sebelum sampai ke tangan konsumen.

\footnotetext{
${ }^{5}$ Peter Mahmud Marzuki, 2009, Penelitian Hukum, Kencana Predana Media Group, Jakarta, h. 93.

${ }^{6}$ Soerjono Soekanto, 1982, Kesadaran Hukum Dan Kepatuhan Hukum, Rajawali, Jakarta, h. 140 .

${ }^{7}$ Laurensius Arliman S, 2015, "Penegakan Hukum Dan Kesadaran Masyarakat", Deepublish, Yogyakarta, h.227
} 
b. Pemahaman hukum yaitu pemahaman pelaku usaha atau produsen mengenai undang-undang yang mengatur tentang standarisasi obat tradisional yang baik. Melalui pemahaman hukum pelaku usaha dapat mengetahui tujuan serta manfaat di undangkannya undang-undang tersebut.

c. Sikap hukum yaitu dalam arti reaksi para pelaku usaha dan produsen saat mengetahui peraturan yang mewajibkan sertifikasi obat tradisional yang di produksi.

d. Pola prilaku hukum yaitu merupakan hal yang sangat penting, karena dapat dilihat apakah suatu peraturan berlaku atau tidak dalam lingkungan pelaku usaha dan produsen tersebut.

Menurut Penjelasan Ibu Ni Putu Marni pegawai dari Kedai

Subur Obat Tradisional Pertokoan Kerthawijaya Ponogoro Denpasar, menjelaskan bahwa ia hanya sebagai pegawai pada toko obat tersebut. Sebelum itu ibu Marni sempat menanyakan kepada penulis obat montalin ini untuk siapa lalu beliau meuju gudang kecil ditempat lain jauh dari rak obat lainnya barulah ia memberi penulis obat tersebut. Ia tidak mengetahui bahwa obat montalin yang dijual pada tempatnya bekerja adalah obat ilegal dan sudah dilarang untuk diperjual belikan oleh BPOM, karena beliau hanya seorang pegawai yang dituntut untuk melayani konsumen sebaik mungkin. Pada waktu yang berbeda penulis datang kembali ke lokasi penelitian untuk mawawancarai Koh Ian selaku pemilik dari Kedai Subur Obat Tradisional. Alasan pemilik usaha memperjualbelikan Obat Tradisional Montalin yang tidak terdaftar BPOM adalah untuk mendapatkan keuntungan selain itu sampai saat ini produsen juga masih memproduksi obat ini karena tingginya permintaan konsumen. Beliau juga mengatakan bulan ini sekitar beberapa minggu yg lalu BPOM Kota Denpasar mengujungi toko tersebut untuk melakukan sidak. (Wawancara, 18 Maret 2019)

Pelaku Usaha dan Produsen sendiri belum memiliki atau belum memahami kesadaran hukum terkait dengan penjualan obat montalin serta pentingnya tata laksana pendaftaran obat tradisional, obat herbal terstandar. Minimnya pengetahuan pelaku usaha dan Produsen tentang 4 indikator kesadaran hukum menjadi tolak ukur bagi kesadaran dalam mengedarkan obat montalin tersebut.

2. Kesadaran Hukum Konsumen Sebagai Pembeli Obat Tradisional Ilegal Montalin di Kota Denpasar

Masalah keamanan konsumen dalam mengkonsumsi obat juga memerlukan perlindungan. Terdapat tiga (3) kategori suatu obat disebut obat palsu. Pertama, bahan takaran dan mereknya sama dengan obat asli, tetapi dibuat oleh produsen bukan pemegang merek. Kedua, mereknya sama tetapi bukan buatan 
produsen yang sama, dan isinya substandar. Ketiga, mereknya sama, tetapi isinya bukan obat dan tidak jelas pembuatannya. ${ }^{8}$

Apabila di kaitkan dengan Pasal 4 Undang-Undang Nomor 8 tahun 1999 tentang perlindungan konsumen maka dapat disimpulkan obat tradisional yang mengandung bahan berbahaya serta tidak memiliki izin edar dari BPOM, tidaklah aman untuk dikonsumsi dan dapat mengancam keselamatan konsumen. Obat tradisional tersebut tidak layak untuk diedarkan di masyarakat karena melanggar hak konsumen sebagaimana yang disebutkan dalam Pasal 4 huruf a Undang-Undang Nomor. 8 Tahun 1999 Tentang Perlindungan Konsumen mengenai hak atas kenyamanan, keamanan, dan keselamatan dalam mengkonsumsi barang dan/atau jasa. ${ }^{9}$

Sebagai pembeli obat montalin, lebih lanjut dijelaskan oleh Ibu Wayan Nurasi selaku konsumen yang mengkonsumsi obat montalin, mejelaskan bahwa, ia menderita penyakit asam urat dan selama mengkonsumsi obat montalin tersebut dapat meredakan rasa sakit yang dirasakan. Ia tidak mengetahui bahwa obat montalin yang ia beli pada kedai subur tersebut adalah obat ilegal dan mengandung bahan kimia obat. Setelah mendapat informasi dari anak beliau melalui media cetak maupun elektronik bahwa obat tersebut ilegal, barulah Ibu Niwayan Nurasi berhenti mengkonsumsi obat tersebut. (wawancara, 19 Maret 2019).

Adanya informasi yang jelas dan benar agar konsumen dapat memperoleh gambaran yang pasti terhadap suatu produk, karena dengan informasi tersebut, konsumen dapat memilih dan memilah produk yang diinginkan/sesuai kebutuhannya serta terhindar dari kerugian akibat kesalahan dalam penggunaan produk. ${ }^{10}$ Perlindungan hukum yang diperoleh konsumen akibat dari penjualan obat ilegal montalin terdapat dalam UndangUndang No 8 Tahun 1999 tentang Perlindungan Konsumen. Pelaku usaha telah melanggar hak-hak konsumen yaitu pada Pasal 4, dan pelaku usaha pun telah melanggar Pasal 8 ayat (1). Mengenai hal perlindungan hukum pemerintah wajib memenuhi hak asasi warganya berdasarkan prinsip anti diskriminasi. ${ }^{11} \mathrm{Hak}$ disini dikaitkan dengan pengertian hak asasi manusia yaitu suatu kebebasan individu yang dimiliknya dengan keleluasaan. ${ }^{12}$

\footnotetext{
${ }^{8}$ Barkatulah, Abdul Halim, 2008, Hukum Perlindungan Konsumen, Nusa Media : Bandung, h.14

${ }^{9}$ Shidarta, Hukum Perlindungan Konsumen,Grasindo, Jakarta, 2000, h.18

${ }^{10}$ Ibid, hal. 41

${ }^{11}$ I Made Udiana, 2016, Kedudukan Dan Kewenangan Pengadilan Industrial, Udayana Press, Denpasar, h. 58.

${ }^{12}$ I Made Udiana, 2018, Industrial Dan Tanggung Jawab Pengusaha Terhadap Tenaga Kerja Terlibat Hukum, Cet I, Udayana University Press, Denpasar, h. 26.
} 


\subsection{Pengawasan BPOM Kota Denpasar Terkait Dengan Peredaran Obat Tradisional Ilegal Montalin}

1. Kewenangan BPOM dalam menerbitkan persyaratan Izin Edar Obat Tradisional di Kota Denpasar

Berdasarkan Peraturan Presiden Nomor 80 Tahun 2017 tentang Badan Pengawas Obat dan Makanan Dalam melaksanakan tugas pengawasan Obat dan Makanan pada Pasal 4, BPOM mempunyai kewenangan: ${ }^{13}$

a. Menerbitkan izin edar produk dan sertifikat sesuai dengan standar dan persyaratan keamanan, khasiat/manfaat dan mutu, serta pengujian obat dan makanan sesuai dengan ketentuan peraturan perundang-undangan;

b. Melakukan intelijen dan penyidikan di bidang pengawasan Obat dan Makanan sesuai dengan ketentuan peraturan perundangundangan; dan

c. Pemberian sanksi administratif sesuai dengan ketentuan peraturan perundang-undangan.

Untuk mendaptakan izin edar obat tradisional sebelumnya harus melakukan pendaftaran terlebih dahulu dengan dua tahap, yaitu pra penilaian dan penilaian. Pra penilaian adalah tahap pemeriksaan kelengkapan serta keabsahan dokumen. Sedangkan tahap penilaian merupakan proses evaluasi terhadap dokumen dan data pendukung. Persetujuan pendaftaran obat tradisional, obat herbal terstandar berlaku 5 (lima) tahun selama masih memenuhi ketentuan yang berlaku dan dapat diperpanjang melalui pendaftaran ulang.

Berdasarkan hasil wawancara dengan ibu Ni Putu Ekayani Scorpiasanty selaku staf dibidang obat dan pangan BPOM Kota Denpasar menjelaskan kewenangan BPOM dalam memberikan izin edar harus sesuai dengan kebijakan teknis operasional di bidang pengawasan Obat dan Makanan. Peraturan perundang-undangan yang diantaranya adalah Peraturan Badan Pengawas Obat dan Makanan Nomor HK.03.1.23.06.11.5629 Tahun 2011 Tentang Persyaratan Teknis Cara Pembuatan Obat Tradisional Yang Baik, Keputusan Mentri Kesehatan Republik Indonesia Nomor 381/MENKES/SK/III/2007 Tentang Kebijakan Obat Tradisional Nasional, Peraturan Kepala Badan Pengawas Obat dan Makanan Nomor: HK.00.05.41.1384 Tentang Kriteria dan Tata Laksana Pendaftaran Obat Tradisional, Obat Herbal Terstandar dan Fitofarmaka, Keputusan Direktur Jenderal Pengawasan Obat dan Makanan Departemen Kesehatan Nomor: 06605/D/SK/X/84 tentang Tata Cara Produksi Obat Tradisional dari Bahan Alam dalam Sediaan Bentuk Kapsul atau Tablet karena obat mintalin ini

${ }^{13}$ Ibid, hal.60 
berbentuk tablet atau kapsul. Masyarakat atau pelaku usaha sudah sangat dimudahkan dengan kemajuan teknologi dimana BPOM memiliki web resmi yang dapat diakses kapan saja disana sudah jelas apapun itu mengenai izin edar, obat tradisional maupun tentang lembaga BPOM sendiri. BPOM Kota Denpasar saat ini menegakan keweangan preventif dengan tahap sertifikasi atau izin edar dan kewenangan represif dengan meriksa seluruh obat tradisional yang akan diedarkan. Biaya izinnya pun cukup terjangkau. ( Wawancara, 11 April 2019)

2. Pengawasan Dan Sanksi Yang Diterapkan Oleh BPOM Kota Denpasar Terkait Dengan Peredaran Obat Tradisional Ilegal Montalin

Sesuai dengan amanat Pasal 30 ayat (1) Undang-Undang Perlindungan Konsumen, dalam menjalankan tugas dan fungsinya sebagai pengawas obat dan makanan dalam wilayah regional Kota Denpasar, BPOM memiliki beberapa program kegiatan pengawasan yakni:

a. Pengawasan Preventif

Tahap upaya preventif atau tahap pengawasan Balai Besar Pengawas Obat dan Makanan di Kota Denpasar sejak berdiri sering melakukan operasi rutin, operasi ini dilakukan 5 sampai 6 kali sebulan. Sasarannya adalah sarana distribusi kedai obat tradisional diseluruh Kota Denpasar.

b. Pengawasan Represif

Tahap selanjutnya adalah tahap represif BPOM, disamping melakukan pengawasan terhadap produk-produk obat tradisional ilegal dan mengandung bahan kimia obat. Balai Besar Pengawas Obat dan Makanan di Kota Denpasar juga melakukan penegakan hukum terhadap penjual nakal yang mengedarkan produk-produk obat tradisional ilegal dan tidak baik digunakan. Jika terbukti demikian maka seorang pelaku usaha dapat dikenakan sanksi administratif dan/atau sanksi pidana bagi pelaku di jerat dengan Undang-Undang Nomor 36 Tahun 2009 tentang Kesehatan Pasal 197 Jo Pasal 106 Ayat (1) dengan pidana penjara paling lama 15 tahun dan denda paling banyak Rp1,5 Milliar. Pemberian sanksi pidana penjara paling lama 15 tahun dan denda paling banyak Rp1,5 Milliar.

Seperti yang disebutkan oleh pasal 4 Peraturan Presiden Nomor 80 Tahun 2017 tentang Badan Pengawas Obat Dan Makanan diatas bahwa dalam melaksanakan tugas pengawasan BPOM mempunyai 3 yang dapat diuraikan yaitu :

a. Menerbitkan izin edar produk dan sertifikat sesuai dengan standar dan persyaratan keamanan, khasiat/manfaat dan mutu, serta pengujian obat dan makanan sesuai dengan ketentuan peraturan perundang-undangan. 
b. Melakukan intelijen dan penyidikan di bidang pengawasan Obat dan Makanan sesuai dengan ketentuan peraturan perundangundangan dengan BPOM memiliki Sistem Pengawasan Obat dan Makanan (SisPOM) yang efektif dan efisien yang mampu mendeteksi, mencegah dan mengawasi produk-produk termaksud untuk melindungi keamanan, keselamatan dan kesehatan konsumennya baik di dalam maupun di luar negeri yang terdiri dari 3 lapis yaitu Sub-sistem Pengawasan Produsen atau Pelaku Usaha, Sub-sistem Pengawasan Konsumen, dan Sub-sistem Pengawasan Pemerintah/BPOM.

c. Pemberian sanksi administratif sesuai dengan ketentuan peraturan perundang-undangan.

Bapak Wayan Eka Ratnata, selaku staf dibidang penindakan BBPOM Kota Denpasar mejelaskan bahwa pengawasan rutin yang dilakukan oleh BBPOM Kota Denpasar adalah dibidang pemeriksaan dan pengawasan. Pengawasan yang kami lakukan biasanya pengawasan preventif maupun represif. Apa bila kami menemukan langsung obat tradisional ilegal montalin saat pengawasan atau saat melakukan sidak kepara pelaku usaha atau pedagang obat tradisional apabila ditemukan obat tradisional ilegal montalin tersebut kami memberikan sanksi berupa sanski administrasi diantaranya seperti peringatan, obat tersebut dimusnahkan langsung ditempat, dan disita. Terkait obat montalin ini kami sudah rutin beberapa kali dalam sebulan sosialisasi dan sidak ke para pelaku usaha dan kami tidak menemukan apa-apa, ini sering terjadi setelah adanya laporan barulah kami tahu. Untuk khasus yg seperti ini maka dapat ditindak lanjuti kejalur hukum. Beliau juga menjelaskan bahwa BPOM Kota Denpasar hanya melalukan penindakan kepada pelaku usaha di Kota Denpasar maupun daerah Bali dan mengenai peredaran obat montalin ini BPOM pusatlah yg berwenang untuk menindak lanjuti produsen. (Wawancara, 11 April 2019)

\section{Penutup}

\subsection{Kesimpulan}

1. Faktor penyebab peredaran obat tradisional ilegal montalin masih di perjual belikan di Kota Denpasar karena Pelaku Usaha dan Produsen sendiri belum memiliki dan belum memahami kesadaran hukum terkait dengan penjualan obat montalin serta pentingnya tata laksana pendaftaran obat tradisional dan gaya hidup masyarakat saat ini sangat mempengaruhi pola konsumsinya obat montalin.

2. Peran BPOM terkait dengan peredaran obat tradisional ilegal montalin di Kota Denpasar cukup jelas bahwa BPOM Kota Denpasar sangat memudahkan pelaku usaha jika ingin 
mendaftarkan produknya. Mengenai peredaran obat tradisional ilegal montalin BPOM Kota Denpasar sudah rutin melakukan pengawasan dibidang pemeriksaan dan apabila ditemukan kasus yang sama lagi maka BPOM tidak segan memberikan sanksi sesuai dengan peraturan yang berlaku.

\subsection{Saran}

1. Bagi para pelaku usaha penting untuk memperhatikan hak dan kewajiban sebagai pelaku usaha. Dan bagi para konsumen juga penting mengetahui mengenai perlindungan apa saja yang didapatkan konsumen apabila mengalami kerugian.

2. Perlu juga adanya kesadaran dari pihak yang berwenang untuk melakukan pengawasan dan pemeriksaan yang lebih intensif terhadap peredaran obat tradisional ilegal montalin agar tidak beredar lagi, sebagaimana yang telah diamanatkan dalam peraturan perundang-undangan yang mengatur mengenai hal tersebut. 


\section{Daftar Pustaka}

\section{Buku}

Barkatulah, Abdul Halim, 2008, Hukum Perlindungan Konsumen, Nusa Media : Bandung.

Laurensius Arliman S, 2015, Penegakan Hukum Dan Kesadaran Masyarakat, Deepublish, Yogyakarta.

Peter Mahmud Marzuki, 2009, Penelitian Hukum, Kencana Predana Media Group, Jakarta.

Purwanto Hardjosaputra, 2008, Daftar Obat Indonesia edisi II, PT.Mulia Purna Jaya Terbit, Jakarta.

Shidarta, Hukum Perlindungan Konsumen, Grasindo, Jakarta, 2000.

Soerjono Soekanto, 1982, Kesadaran Hukum Dan Kepatuhan Hukum, Rajawali, Jakarta.

Udiana, I Made, 2015, Kedudukan Dan Kewenangan Pengadilan Hubungan Industrial, Udayana University Press, Denpasar. , 2018, Industrialisasi \& Tanggung Jawab Pengusaha Terhadap Tenaga Kerja Terlibat Hukum, Udayana University Press, Denpasar.

\section{Artike1}

Gede Jaya Kesuma dkk, 2018, "Peranan Balai Besar Pengawas Obat Dan Makanan Provinsi Bali dalam memberikan perlindungan terhadap konsumen dengan peredaran obat yang mengandung zat berbahaya (Policresulen)" , Jurnal Fakultas Hukum Universitas Udayana,Denpasar, https://ojs.unud.ac.id/index.php/kerthasemaya/article/vie $\underline{\mathrm{w} / 41656}$. Diakses pada tanggal 17 Juni 2019

G. Eka Putra Pratama Arnawa dkk, 2018 "Pengawasan Terhadap Perusahaan Yang Mengedarkan Obat-Obatan Impor Tanpa Izin Edar", Jurnal Fakultas Hukum Universitas Udayana, Denpasar,https://ojs.unud.ac.id/index.php/kerthasemaya/ article/view/44828 . Diakses pada tanggal 17 Juni 2019

Tribun News, 2015, Obat Kuat yang Kini Tren di Bali Ternyata Mengandung Bahan Kimia, Serial Online, Oktober- 
November,http://www.tribunnews.com/regional/2015/09/1 0/obat-kuat-yang-kini-tren-di-bali-ternyata-mengandungbahan-kimia . Diakses pada tanggal 30 Oktober 2018

\section{Perundang-undangan}

Undang-Undang Dasar Negara Republik Indonesia Tahun 1945

Kitab Undang-Undang Hukum Perdata

Undang-Undang Nomor 8 Tahun 1999 tentang Perlindungan Konsumen

Undang-Undang Nomor 36 Tahun 2009 tentang Kesehatan

Peraturan Presiden Republik Indonesia Nomor 80 Tahun 2017 Tentang Badan Pengawas Obat Dan Makanan

Peraturan Badan Pengawas Obat dan Makanan Nomor HK.03.1.23.06.11.5629 Tahun 2011 Tentang Persyaratan Teknis Cara Pembuatan Obat Tradisional Yang Baik

Keputusan Mentri Kesehatan Republik Indonesia Nomor 381/MENKES/SK/III/2007 Tentang Kebijakan Obat Tradisional Nasional 